breathing of lambs, $£ 13,200$ to the Department of Physics, Birkbeck College, University of London, for two research fellowships for three years for work on protein and virus structure, and $£ 15,000$ over five years to the Nuffield Research Group in the Department of Metallurgy at the Imperial College of Science and Technology, University of London, to tide the group over the time until full support is forthcoming from industry and the College for its work on the theory and practice of the extraction of metals from ore.

\section{THE MINING INDUSTRY IN BRITAIN}

NTERESTING human documents, though written 1 primarily as the technical record of the work of the Mines Inspectorate in England, are a series of separate reports of the divisional inspectors of five divisions*. Though ostensibly all written with the same objective, they have a refreshing variety, and are indications of the widely differing characters of the separate coalfields, which have required from a centrally controlled authority differences of approach appropriate to local conditions and practices.

Naturally one's first search among these pages must be for the signs of improvement in the statistics of the killed and injured each year that must inevitably, one would think, take place as the result of the considerable attention that is given to the problem of safety. In some divisions one finds an encouraging record of betterment; in others there are to be found an almost discouraging fluctuation of figures from one year to another that must have some deep-seated causes. On reading the separate reports, it very soon becomes apparent that the character of the pits varies widely - thin seams and thick seams, high standards of mechanization, less-developed ones, and wide differences in the character of the mining problems. Perhaps the common problem is the stubbornness of human nature, shown in the repeated instances of accidents due to individual carelessness that has resulted in neglect of regulations framed for their prevention. The major sources of fatal accidents are falls of roof and haulage breakdowns, particularly runaways.

Interesting to the layman in these reports are the many references to the development of new methods and appliances culled from a wide field of experiment carried out both in and outside the industry of coal mining - thus the colorimetric testing of coal dust, the new developments of electric haulage, the ever-advancing character of the new devices for dealing with roof support, the vital problem of the miner, and the many new types of machine for coal cutting. The introduction of machine mining has brought in its train new problems in dust suppression. Following the experience which many mining engineers have had of the effect of water on the mining of coal, there is growing up a body of opinion which believes in this development, which must reduce the use of coal-cutters and shot firing and thus reduce the production of dust. In this application

* Ministry of Fuel and Power. Reports of H.M. Inspectors of Mines under the Coal Mines Act, 1911, for the year 1953. North Eastern Division. By C. W. Scott. Pp. il +30. 2s. net. West Midland and Southern Division. By J. E. Henshaw. Pp. il +24. 18. 6d. net. Northern Division. By W. Brown. Pp. ii +30 . 18. 6d. net. North Western Division. By G. Hoyle. Pp. ii $+26+5$ plates. 28. net. don: H.M. Stationery Ofhco, 1954.) a long hole parallel to the coal-face is drilled, filled with explosive, and then high-pressure water admitted, the objective being to soften the coal.

In spite of all the research and care taken in mine air analysis and other precautions, explosions of fire damp still occur-a pertinent reminder that in no branch of mining technology can it be said that all the problems have yet been solved.

On the surface and underground, good progress has been made in the improvement of the standards of illumination. The removal of glare and shadows is an important feature of such advancement.

Health and welfare, training and education occupy an essential place in the manifold activities of the mining industry. Finally, it is interesting to note that the first electrically driven, horse-cleaning vacuum equipment operated by a certified flame-proof motor and switchgear was installed at the beginning of the year in the underground stables, 3,000 yards from the pit bottom at Hamstead Colliery. Should it be called an equus-cleaner?

R. J. SARJANT

\section{OVERSEAS FOOD CORPORATION}

\section{ANNUAL REPORT}

THE Overseas Food Corporation is now concerned solely with investigations, first to ascertain experimentally crop and stock potentialities, with their cultural and husbandry requirements; second, to determine their practical limitations and economics, by applying the findings of the specialists to large-scale trials by farmers; and third, by incorporating in the large-scale trials variations in farming methods, to ascertain which form is likely to prove most productive and yield the greatest return as and when the area is developed. The annual report and statement of accounts for the year ended March 31, 1954*, record steady progress under the first heading. The continued soil surveys, soil fertility studies and the fertilizer experiments are revealing the percentages of the various soil types to be found in the areas, their suitability to the range of crops under trial, their mechanical condition and their response to fertilizer treatment. Considerable progress has been made in the study of rosette disease of groundnuts, and that on the mechanism of resistance of Mwitunde to rosette disease indicates reasonable hopes of selecting a strain combining high yield, low aphid reproduction, low percentage of infective aphids and perhaps some tolerance to the usually severe effect of the virus on yield. Indications are that groundnuts may become an important crop in the rotation at Nachingwea and merit further trial at Urambo in the $1955-56$ season.

The second type of investigations was severely checked by the drought throughout Tanganyika during the 1952-53 crop season; but much information was obtained on methods of cultivation desirable under dry-farming conditions. Variations in the third class included experiments with farms of 2,000 acres, 1,500 acres and 1,000 acres, fully mechanized and under European supervision, to determine the pattern of farming best suited to local conditions and the most economical size, while the possibilities of improving peasant farming on a group basis are being examined under the African Tenant Scheme.

* Overseas Food Corporation. Annual Report and Statement of Accounts for the year ended 31st March, 1954. Pp. iv +70. (London 
The Corporation maintains close touch with the East African Agricultural and Forestry Research Organization and with the East African Tsetse and Trypanosomiasis Research and Reclamation Organization, as well as with departments of the Tanganyika Government and other bodies; but the work of the Scientific Department is presented on a regional basis in what forms the longest chapter of the report. Among some points of interest are the slight increase in plant population and the big increase in yield obtained in experiments on the control of weeds in maize with 'Fernoxone' at Urambo ; the absence of any significant increase in yield of soys bean and maize on deep placement of triple phosphate fertilizer although the standard method of placing fertilizer gave highly significant increase; the identification in South Tanganyika of the maize rust Puccinia polysora Underw.; and the continued trials and experiments on the development and improvement of agricultural machinery. Soil fertility studies were restricted to maize, and little progress is reported in the determination of the phosphate status of soils by chemical tests.

\section{METEORIC PARTICLES IN THE ATMOSPHERE}

$Z^{1}$

DENEK SVESTKA, Astronomical Institute of the Czechoslovak Academy of Sciences, Ondřejov, has a paper in Bulletin of the Astronomical Institutes of Czechoslovakia (5, No. 5; Sept. 1, 1954), in which he criticizes F. Link's theory of the fall and absorption influence of meteoritic particles in the atmosphere. This theory has been explained in some of the B.A.C. issues over several years, and the time of fall $T$ in seconds through $100 \mathrm{~km}$. may be expressed by Link's approximate formula:

$$
\log _{10} T=C-1.5 \log _{10} \rho
$$

where $C=1.4$ for metallic particles and 1.6 for stony particles, the radius of the particles in all cases being $\rho$. According to this formula, the time of fall of 30-100 days would correspond to particles the diameters of which in the limit would conform with the relation $4 \mu<2 p<14 \mu$. From a study of the absorption influence of particles of different diameters Link also constructed an empirical formula for the number $n$ of particles of iron and silicates of different sizes :

$$
\log _{10} n=\text { constant }-600 p
$$

and making use of other data, concluded that the absorption in a layer of meteoric dust is caused predominantly by particles with diameters from $2 \mu$ to $6 \mu$.

Svestka has now examined Link's assumptions and deductions and concludes that the latter are inaccurate in many cases. Observations of absorption effects of a dust-layer in the atmosphere during lunar eclipses can be satisfied only when the optical thickness of the layer is equal to 0.01 as a minimum. A table gives for different values of $\rho$ the minimum possible time of fall for which the above optical thickness is assumed, and also the maximum quantity of meteoric matter falling on the earth, which, it is shown, cannot exceed $5 \times 10^{-14} \mathrm{gm}$. $\mathrm{cm}^{-2}$ sec.-1, and proves that it is quite impossible-from the optical point of view-that the observed absorption could be caused by particles larger than $1 \mu$. Link's theoretical conclusions were based on Thomsen's results of collections of atmospheric iron particles, the diameters of which ranged from $10 \mu$ to $80 \mu$; but there is very strong evidence from the collection of similar particles in the industrial country of Jens that the meteoritic nature of Thomsen's particles must be open to considerable doubt. It seems probable that meteoric dust is formed by much smaller particles of the order of $10^{-5}-10^{-6} \mathrm{~cm}$., and it is suggested that a study of the sky-light polarization, during and after the activity of strong meteor showers, might provide a decisive answer to the problem under investigation.

\section{THE EARTH'S EXTERIOR ATMOSPHERE AND THE COUNTERGLOW}

TNDER this title, the Canadian Defence Research Board has published a second augmented edition of material prepared by E. R. Hope*. In the main this consists of Mr. Hope's translations of recent Russian papers (two more than the first edition) of very great interest concerning observations and theories about the outermost atmosphere of the earth.

The Russian astronomers, Astapovich, Fesenkov, Divari and Karimov, have a particular claim to our attention, for they enjoy in some parts of their country a clarity of the sky which is unrivalled and which is a great asset to the observations concerning the outermost atmosphere and the counterglow. Their revolutionary theories are based in part on new observational discoveries, and their speculations make good use of all the knowledge there is on the subject. They establish that the observational material is in accord with the suggestion that a gaseous tail stretches away from the earth, resembling the tail of a comet, in the direction opposite to that of the sun. They do not suggest that the processes responsible for the heating of the outermost atmosphere or for the acceleration of the gas spraying off in the tail are at all understood.

The translator's foreword of twenty-six pages aims at reviewing the entire subject in a critical manner, and at establishing the relation between these outer atmosphere researches and those connected with magnetic and auroral effects. Much of this could come under severe criticism, and one suspects that most of the authors mentioned would disagree with the arguments presented that oppose their points of view, but equally with those that are in their favour. Those who are concerned with these subjects will have to go over the literature and the arguments for themselves, anyway; and those who would appreciate a passing acquaintance cannot be advised to gain it here, for they are unlikely to appreciate that another review article might, with equal justification, reverse very many of the arguments.

The translations of the Russian papers read well, and make a valuable contribution to the literature accessible to most Western astronomers and to those concerned with upper atmosphere research.

T. GOLD

* The Earth's Exterior Atmosphere and the Counterglow : The Counterglow as Related to Modern Geophysical Theories, with Seven Recent Russian papers. Collected and translated by E. R. Hope. Second edition. (T 65 R.) Pp. xxvili + 52. (Ottawa: Def 